\title{
Efeito dos eventos ENOS e das TSM na variação pluviométrica do semi-árido paraibano
}

\author{
João M. de Moraes Neto' ${ }^{1}$, Marx P. Barbosa ${ }^{1} \&$ Alexandre E. de Araújo ${ }^{2}$
}

\begin{abstract}
RESUMO
Os efeitos dos eventos ENOS (El Niño Oscilação Sul) e das TSM (temperatura da superfície do mar) do Atlântico sobre a pluviometria do semi-árido paraibano foram avaliados utilizando-se o teste de Wilcoxom-Mann-Whitney, com base nos dados pluviométricos do período 1970/2000, cedidos pelo LMRS-PB (Laboratório de Meteorologia Recursos Hídricos e Sensoriamento Remoto do Estado da Paraíba). Os resultados mostraram haver uma diferença significativa a nível de $5 \%$ de probabilidade entre os períodos com e sem influência dos eventos ENOS e das TSM do Atlântico para o Estado. Para os municípios de Sousa (Alto Sertão) e Sumé (Cariri Ocidental) esta diferença também foi de 5\%, porém para o município de Picuí (Seridó/Curimataú) ela foi de 10\%, evidenciando que os eventos ENOS e as TSM do Atlântico têm influência direta sobre as variações dos valores médios dos índices de precipitação dos municípios avaliados.
\end{abstract}

Palavras-chave: El Niño, influência, temperatura, Paraíba

\section{Effects of the ENSO events and variation of SST on the rainfall in semi-arid region of Paraíba State}

\begin{abstract}
The ENSO (EI Niño South Oscillation) events and the Atlantic sea surface temperature (SST) effects on the rainfall in the semi-arid region of State of Paraíba, Brazil, were evaluated using the Wilcoxom-Mann-Whitney test, based on the rainfall data for the period 1970-2000, furnished by the LMRS-PB (Meteorological, Water Resources and Remote Sensing Laboratory of the State of Paraíba). The results show that a significant difference, at the level of $5 \%$ of probability, exists related to periods with and without influence of ENOS events and of Atlantic SST for the State of Paraíba. For the municipalities of Sousa (Alto Sertão region) and Sumé (Cariri Occidental region) this difference also was significant at $5 \%$, however for the municipality of Picuí (Seridó/Curimataú region) it was significant at $10 \%$. This fact evidences the direct influence of the ENOS events and of the Atlantic SST on the variability of the mean values of the rainfall rates in the evaluated municipalities.
\end{abstract}

Key words: El Niño, influence, temperature, Paraíba

1 UAEAg/CCT/UFCG. CEP 58109-930, Campina Grande, PB. Fone: (83) 3310 1185. E-mail: Moraes@deag.ufcg.edu.br, marx@deag.ufcg.edu.br

2 Doutorando em Engenharia Agrícola, UFCG. Fone: (83) 3310 1185. E-mail: Alex@deag.ufcg.edu.br 


\section{INTRODUÇÃO}

El Niño Oscilação Sul (ENOS) é um fenômeno de interação oceano-atmosfera, associado às alterações dos padrões normais da TSM (temperatura da superfície do mar) e dos ventos alísios na região do Pacífico Equatorial, entre a Costa Peruana e a Austrália. Além da temperatura do mar, o fenômeno ENOS pode ser medido pelo Índice de Oscilação Sul (IOS), que é a diferença média da pressão a nível do mar entre os setores do centro-leste (Taiti/Oceania) e oeste (Darwin/Austrália) do Pacífico Tropical. Este índice está relacionado ao aquecimento/resfriamento das águas na região (CLIMERH, 2002). Moura \& Shukla (1981) estudando as correlações entre os valores das anomalias de TSM em março, no Atlântico Tropical, e as chuvas médias (desvios normalizados) de Quixeramobim e Fortaleza (Estado do Ceará), encontraram uma configuração dipolar. As correlações positivas no Atlântico Sul significam que valores de TSM mais quentes aumentariam a evaporação elevando a convergência do fluxo de umidade, diminuindo a estabilidade estática da atmosfera em baixos níveis favorecendo o aumento da precipitação no Nordeste.

Entre as conseqüências do ENOS podem ser destacados: o aumento das precipitações no sul da América do Sul, atingindo proporções catastróficas como em 1983, e a seca nas regiões Norte e Nordeste do Brasil para o mesmo período (Brasil, 1997).

Dentre os efeitos mais evidentes do ENOS na região Nordeste, são as variações pluviométricas que, efetivamente, devem receber maior destaque, pois delas dependem, praticamente, todas as atividades desenvolvidas no meio rural, com influência direta na economia do semi-árido.

O semi-árido paraibano é caracterizado por baixas médias pluviométricas e altos índices de evapotranspiração, e se faz mister enfatizar que a distribuição pluviométrica se dá em um período muito curto do ano, com uma distribuição temporal e espacial bastante irregular.

Um dos problemas agravados pelas estiagens nas regiões semi-áridas é a expansão dos núcleos de desertificação. Os fenômenos meteorológicos que contribuem para a desertificação são, por ordem de importância, as secas, as avalanches, a erosão do vento e a variabilidade climática (Nicholson, 1999).

Objetivou-se, com este trabalho, estudar os efeitos dos fenômenos ENOS, especialmente dos megaeventos sobre a pluviometria do semi-árido paraibano.

\section{MATERIAL E MÉTODOS}

O trabalho foi desenvolvido no LMRS (Laboratório de Meteorologia e Recursos Naturais e Sensoriamento Remoto do Estado da Paraíba) no Centro de Tecnologia e Recursos Naturais da Universidade Federal de Campina Grande, cujos dados pluviométricos do período estudado (1970 a 2000) foram obtidos. Tomaram-se como base, além dos dados pluviométricos gerais para o estado e das regiões Cariri/Curimataú, Sertão e Agreste/Litoral, dados pluviométricos de três municípios distintos (Figura 1) e representativos das regiões semi-áridas do Estado (Picuí, no Curimataú, Sousa, no Sertão e Sumé, no Cariri). Os dados de produção foram obtidos da FIBGE (2001).

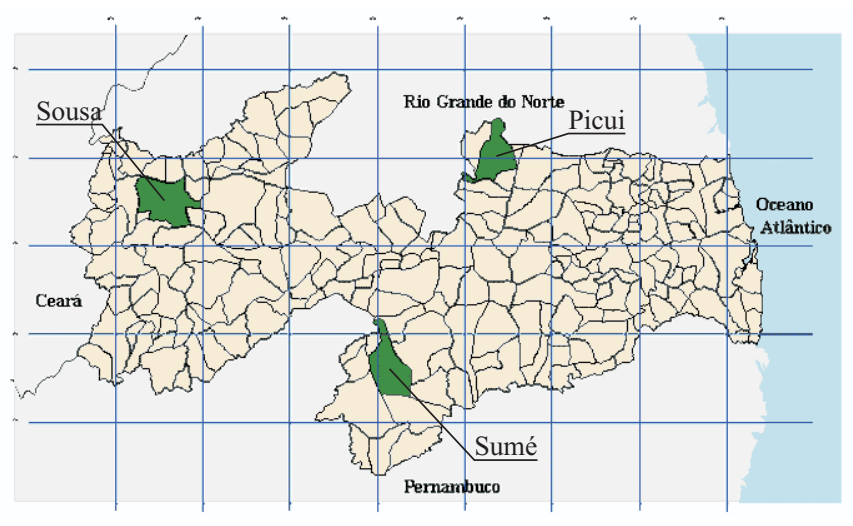

Figura 1. Localização da área de estudo no Estado da Paraíba

Na avaliação dos efeitos da mudança global envolvendo o evento ENOS e as TSM do Oceano Atlântico na precipitação do Estado da Paraíba, foi utilizado o programa Assistat versão 6.2 teste de Wilcoxom-Monn-Whitney.

\section{RESULTADOS E DISCUSSÃO}

Na Figura 2 são apresentadas as curvas de distribuição média das precipitações dos anos de El Niño, La Niña e Neutros, para as décadas de 70, 80 e 90, além da curva integrada das precipitações médias anuais do Estado.

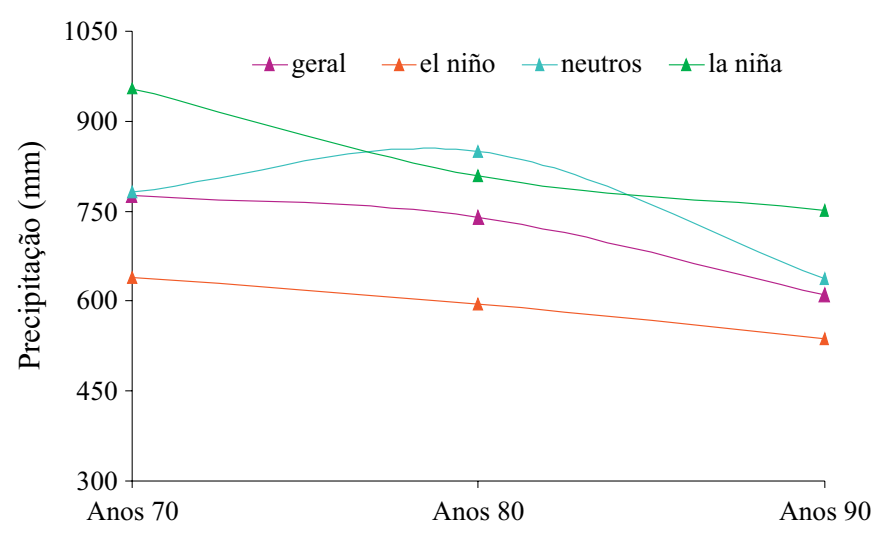

Figura 2. Precipitação média nas décadas de 70, 80 e 90, para o Estado da Paraíba

Tanto as curvas por evento como a curva geral, mostraram um padrão semelhante durante as três décadas, ou seja, um comportamento decrescente, indicando uma diminuição nas médias pluviométricas, mesmo para os anos considerados normais. É importante e interessante salientar que as mudanças globais devem, de alguma forma, ter uma influência pontual nos municípios estudados que interferem, possivelmente, na pluviometria; por sua vez, essas mudanças estão, quiçá, 
sendo regidas por fatores como o desmatamento em grande escala, a poluição das águas e do ar, pela emissão de gases tóxicos na atmosfera.

É possível observar que a curva referente ao período influenciado pelos eventos El Niño é a que representa as menores precipitações para as três décadas, estando bem abaixo das outras mas com o mesmo padrão de queda das precipitações observado para a curva dos anos La Niña, na década de 1980, com acentuação na década de 1990, períodos em que aconteceram os megaeventos El Niño (1982/83 e 97/98) levantando, assim, a hipótese de que os megaeventos El Nino afetam, efetivamente, os índices pluviométricos da região. A correlação entre o evento El Niño com as TSM do Oceano Atlântico mostrou que:

a) para o El Niño 82/83, o Atlântico Norte apresentou, em 1982, anomalias negativas no período de julho a dezembro, enquanto no Atlântico Tropical a anomalia foi positiva e, no Atlântico Sul, negativa. Em 1983, para o período de janeiro a julho, o Dipolo do Atlântico ficou bem caracterizado com anomalias positivas no Atlântico Norte e negativas no Atlântico Sul. As condições de anomalia negativa no Atlântico Sul não são favoráveis à ocorrência de chuvas no semi-árido acentuando-se, essas condições, em anos El Niño.

b) para o EL Niño de 1997/98, as anomalias do Atlântico Norte e do Atlântico Tropical para o período de junho de 1997 a julho de 1998, foram todas positivas e, para o Atlântico Sul, o período de junho a dezembro de 1987 caracterizou-se por anomalias negativas e, para o ano de 1998, de janeiro a julho, por anomalias positivas, o que poderia explicar certo aumento, embora discreto, das precipitações na região sertaneja (Figura $3 \mathrm{~B}$ ).

A curva representativa do evento La Nina, em termos de quantidade de chuvas, mostra anos com médias pluviométricas próximas ou um pouco acima das médias gerais do Estado e bem acima das médias do período El Niño.

As Figuras 3A, B e C mostram a variação da pluviometria das regiões do Cariri/Curimataú, Sertão e Agreste/Litoral para o período de 1994 a 1998 pode-se, observar, neles, que o efeito megaevento El Niño 1997/98, foi bem mais severo no Cariri/Curimataú e no Sertão do que no Agreste/Litoral, onde este foi mais moderado. Além disso, estas figuras dão uma idéia mais concreta do período de atuação do evento, desde quando ele começou e quanto durou.

Na Figura 3 também é possível observar como é grande a variação da precipitação com relação ao aspecto temporal para as diferentes regiões do Estado e como as médias pluviométricas no segundo semestre dos anos estudados diminuem, principalmente nas regiões do Cariri/Curimataú e no Sertão nas quais, em geral, as médias de julho a dezembro atingem valores mínimos.

É possível notar, também, não apenas que a quadra chuvosa para o Cariri/Curimataú assim como para o Sertão, está sempre entre o período que vai de janeiro/fevereiro a maio/ junho, enquanto para o Agreste/Litoral vai de fevereiro/março a julho/agosto.

Para o Cariri/Curimataú e Sertão, o ano de 1996 foi o que apresentou os maiores picos de precipitação, enquanto para o Agreste/Litoral isto ocorreu no ano de 1994, o que denota a variabilidade espacial das chuvas no Estado.

A Figura 3 mostra que as menores precipitações durante a atuação do mega El Niño de 1997/98, ocorreram no ano de 1998 e que, no ano de 1997, as chuvas praticamente foram normais, visto que o período chuvoso foi anterior à instalação

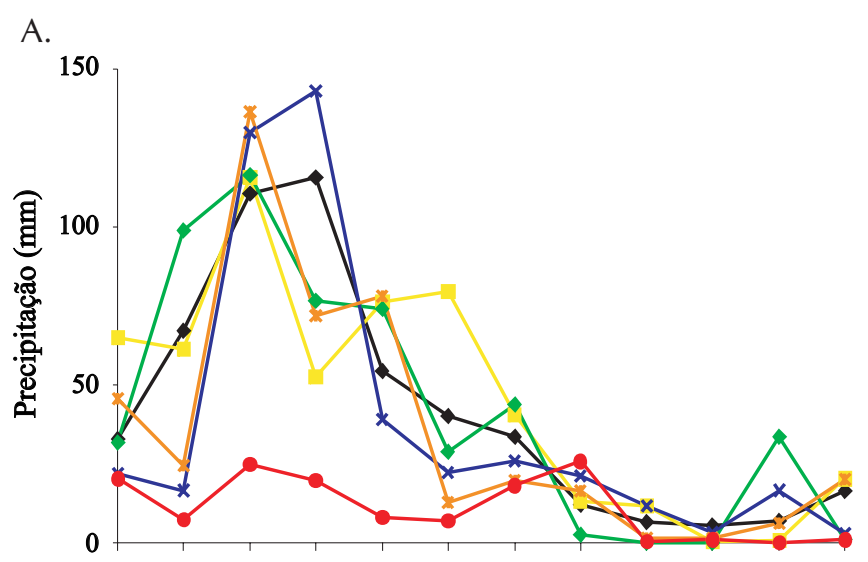

B.

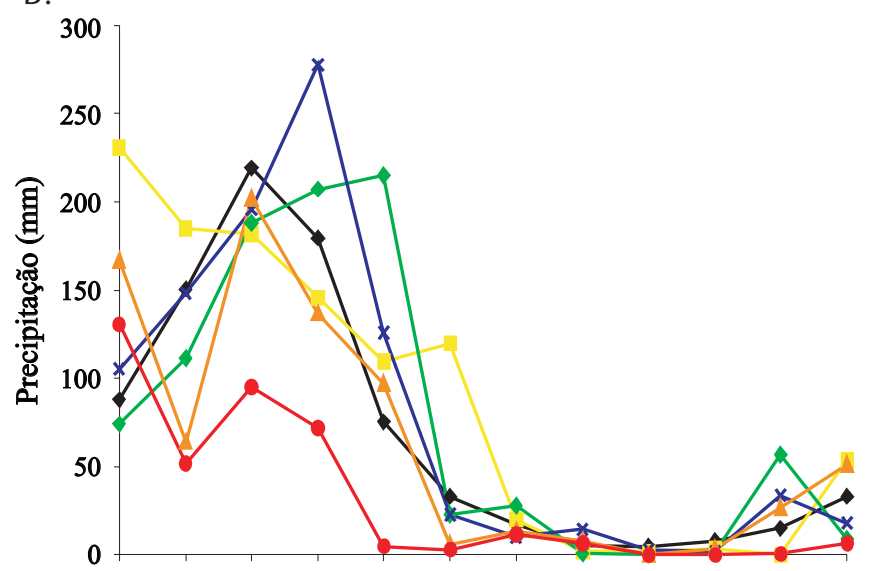

C.

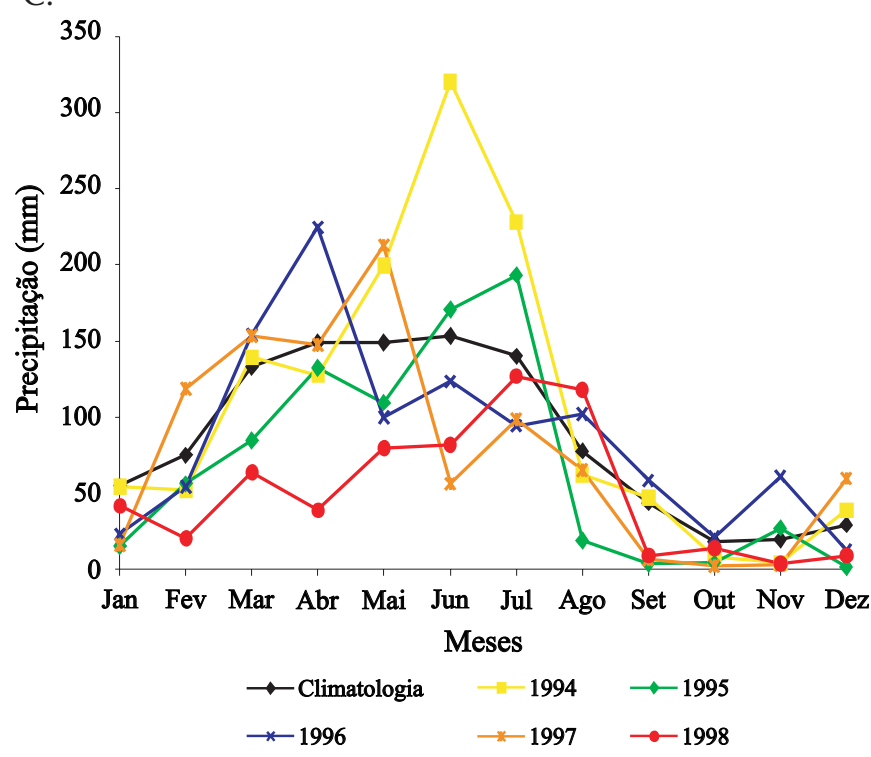

Figura 3. Totais pluviométricos das regiões do Cariri/Curimataú (A), Sertão (B) e Agreste/Litoral (C) do Estado da Paraíba.

Obs. O El Niño de 1997/98 teve início em final de abril início de maio de 1997 e se prolongou até praticamente o final de junho de 1998 
do evento. Para o Estado da Paraíba e para as áreas testes estudadas, os efeitos deste megaevento foram mais caracterizados no ano de 1998, quando todo o semi-árido paraibano esteve sob o domínio de uma das mais severas e prolongadas secas.

Na região do Agreste/Litoral já se observa tendência negativa em relação à climatologia; no entanto, a curva para o ano de 1997 indica uma similaridade com a do ano de 1996. O final do ano de 1997, a partir do último quadrimestre já apresenta, para as 3 regiões, uma conformidade do padrão - precipitação praticamente nula que, aparentemente, parece ser uma resposta direta ao máximo desenvolvimento do megaevento El Niño no Pacífico mas, fazendo-se um paralelo para a região, este fato não é tão significativo, uma vez que, normalmente, esta época é considerada de seca regular (normal).

No ano de 1998 as influências do megaevento EL Niño e das TSM do Atlântico, se tornam mais evidentes. No Estado da Paraíba a estação chuvosa, ou quadras chuvosas, como regionalmente é chamada, tem início no mês de janeiro, na região do Alto Sertão e se prolonga até o final de agosto, na região do Litoral; desta forma, o ano de 1998, desde o início, já se apresenta anômalo, com precipitações muito baixas e irregulares nas regiões do Cariri/Curimataú com um índice de 25 mm e do Sertão com um índice em torno de $75 \mathrm{~mm}$ para o período de janeiro a junho. Esta baixa pluviosidade, que se estendeu ao longo de todo o ano de 1998, somado aos meses de seca regular a partir de junho do ano anterior, definiu um longo período de estiagem, totalizando aproximadamente 18 meses. Mesmo com o início na segunda metade do ano de 1998 de um evento La Niña Moderado, praticamente não houve mudança dessa situação climática em todo o Estado; Somente para a região do Agreste/Litoral é que se observa tendência de aumento das precipitações nos meses de julho e agosto, em época pós EL Niño e pré-início da seca regular; em 1999 ocorreu um aumento do índice pluviométrico, mas não homogêneo, a exemplo do município de Sumé, que alcançou apenas 297,8 mm ao ano, valor bem abaixo de sua média anual histórica. Para este ano, tanto o Atlântico Norte como o Sul apresentaram anomalias positivas, enquanto o Atlântico Tropical, anomalias negativas, não se caracterizando, assim, o Dipolo do Atlântico.

Este período do El Niño 1997/98 foi, sem dúvida, um verdadeiro desastre para o Estado, com queda de produção em quase todos os setores produtivos da agropecuária. Os dados da FIBGE (2001) mostram que a produção de feijão em Picuí caiu de 540 t em 1997 para apenas 40 t em 1998. Esses dados se tornam ainda mais expressivos e surpreendentes quando se observa que esta quebra de produção é causa direta dos efeitos climáticos, pois a área plantada foi praticamente a mesma nos dois anos. A justificativa para o ano de 1997 ter sido de boa produção, apesar de ser o ano de instalação do megaevento El Niño 1997/98, reside no fato de que a fase madura do evento se dá depois da metade do ano, atingindo sua máxima intensidade no início do ano seguinte, o que justifica a possibilidade de boa colheita no ano de instalação do evento, já que a mesma se verifica ainda no primeiro semestre. Em Sousa, o número de cabeças de gado que em 1996 começava a recuperar-se da longa estiagem de 1991 a 1994 e já contabilizava 35.957 cabeças, caiu para 28.157 em 1997 e para 26.750 em 1998 (FIBGE, 2001).

A Figura 4 mostra a curva das médias pluviométricas referentes aos anos de El Niño para o município de Sousa (sertão paraibano), onde se observa que, praticamente $80 \%$ dos valores ficaram abaixo da média pluviométrica do município. A análise feita no Assistat, utilizando-se o teste de Wilcoxon-Mann-Whitney, mostrou que existe uma diferença significativa a nível de 5\% de probabilidade entre essas médias, confirmando a hipótese da influência do evento ENOS na climatologia do município de Sousa, para o período de 1970 a 2000.

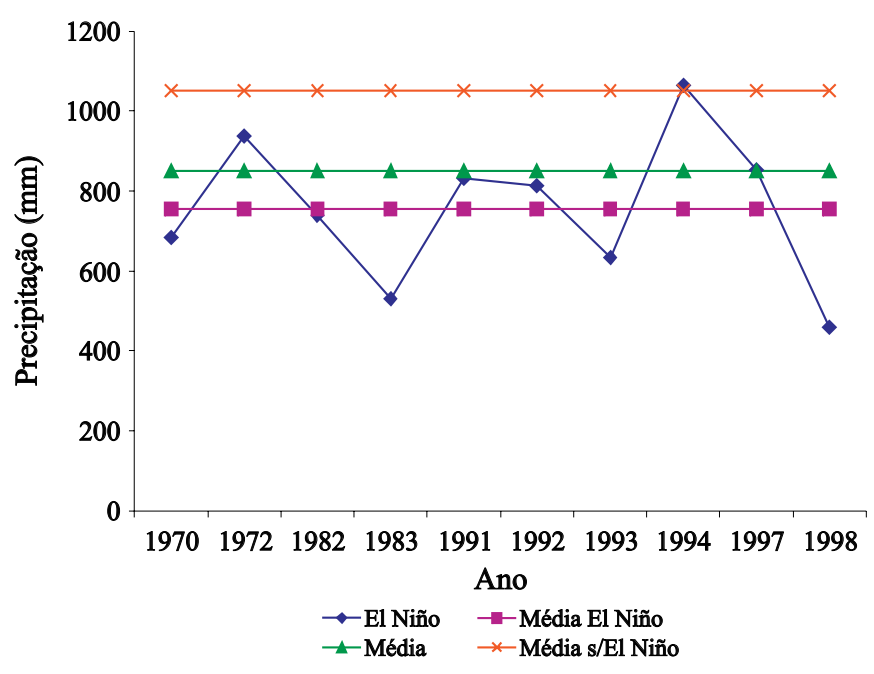

Figura 4. Médias pluviométricas referentes aos anos de El Niño - Sousa, PB

Nas análises pluviométricas relacionadas aos eventos ENOS associados às TSM do Oceano Atlântico é preciso levar em consideração a fase madura do evento, uma vez que a evolução típica do fenômeno mostra que se inicia no começo do ano, atinge sua máxima intensidade durante o mês de dezembro daquele ano e o mês de janeiro do ano seguinte e apenas começa a se enfraquecer na metade do segundo ano (CPTEC, 2000); portanto, na grande maioria das vezes o efeito mais forte do evento, na região do semi-árido, se dá no ano seguinte ao da sua instalação. Outro fator importante e que não se pode deixar de relacionar nas análises, é a efetiva relação do IOS (Índice de Oscilação Sul), com a intensidade dos efeitos a que este fenômeno está relacionado.

Questão relevante com relação à influência do fenômeno, é que a média representada na curva pela cor verde (Média) foi calculada a partir dos dados pluviométricos gerais da região, incluindo-se, assim, os anos de megaeventos. Sem duvida, quando se calcula esta média excluindo-se os anos de El Niño, curva laranja (Média s/El Niño), fica mais explícita a influência do evento e, praticamente, toda a curva representativa do El Niño fica quase $300 \mathrm{~mm}$ ao ano abaixo deste valor.

A exemplo do El Niño de 1997/98, o megaevento de 1982/ 83 também trouxe conseqüências desastrosas para a região de Sousa, com perda de colheita e redução drástica na pecuária. Segundo dados da FIBGE (2001) o número de bovinos, que era de 42.120 em 1981, caiu para 33.697 em 1982 e para 
apenas 23.589 cabeças em 1983. É importante ressaltar que esta redução ocorreu não por planejamento dos produtores diante da vulnerabilidade e do risco a que estavam expostos, mas por falta de sustentabilidade que, invariavelmente, resulta em perdas.

Essas perdas econômicas, que são traduzidas em grandes prejuízos para o Estado, têm como pano de fundo a falta de políticas públicas adequadas capazes de municiar os produtores rurais de informações e assistência técnica, como parte, inclusive, de um sistema de alerta antecipado, baseado nos prognósticos climáticos, capazes de minimizar a vulnerabilidade em que os mesmos se encontram, já que o risco vai existir sempre.

A Figura 5 representa a variação das médias pluviométricas de Sousa referente aos períodos sob influência dos eventos La Niña, podendo-se observar aumento da precipitação com relação à média do município em todos os anos em que o evento se fez presente. Com relação ao Nordeste brasileiro e, especialmente, ao semi-árido, os anos La Niña têm trazido benefícios às regiões afetadas, melhorando os níveis dos reservatórios, propiciando o aumento das produções agrícolas e pecuárias, favorecendo a agricultura de subsistência e possibilitando a permanência do homem no campo.

Assim como ocorre com o evento El Niño, o La Niña também está diretamente relacionado com o IOS, sendo que, neste caso, quanto maior for este índice maior será a influência do evento nas regiões afetadas. É possível observar, na Figura 5, que os picos de precipitação ocorreram principalmente em 1988/1989 e 1995/1996, anos em que se verificaram os maiores índices de oscilação sul do período estudado.

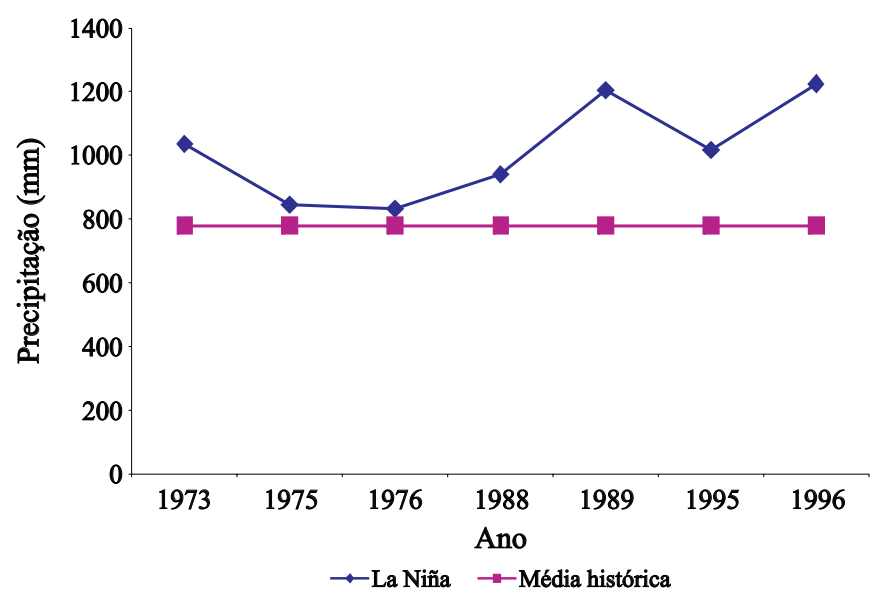

Figura 5. Médias pluviométricas referentes ao período La Niña, Sousa, PB

Um dado importante de ser mencionado, segundo CLIMERH (2002) é que os eventos La Niña apresentam maior variabilidade e ocorrem com freqüência menor que os eventos El Niño. De 1900 a 1997 ocorreram 28 episódios El Niño e apenas 18 La Niña.

Como reflexo positivo deste período na agricultura podese citar, segundo dados da FIBGE (2001), o aumento da produção de coco para o município, que passou de 74 mil em 1985 para 150 mil unidades em 1986, comprovando o as- pecto favorável do efeito La Niña para regiões semi-áridas.

A evolução da pecuária bovina de Sousa, indicada na Figura 6, deixa bem caracterizado como as variações da produção se correlacionam com os eventos ENOS.

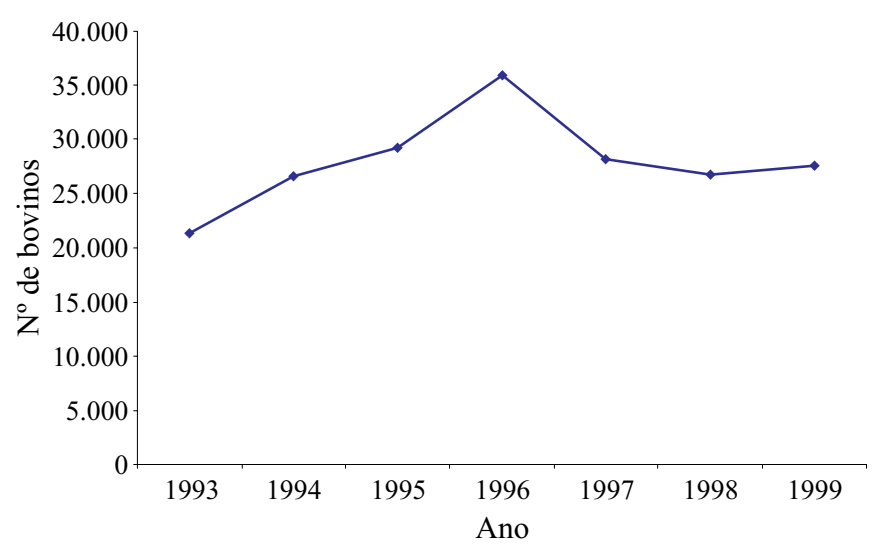

Figura 6. Variação do efetivo bovino em Sousa, face aos anos ENOS

De 1994 para 1996 (ano de La Niña) observou-se acréscimo do número de cabeças, passando de 26.630 para 35.957 (pico) voltando a cair para 26.750 cabeças em 1998 (ano de El Niño).

A Figura 7 mostra a variação pluviométrica de Picuí (Seridó Oriental) relativa aos anos El Niño, na qual é possível observar, que na maior parte do período, cerca de 65\% dos valores ficaram abaixo da média histórica da região.

Os anos dos megaeventos, ou seja, de 1982/1983, 1997/ 1998 e de 1992/1993, foram os que apresentaram as mais baixas precipitações médias da região, ficando muito aquém da média histórica; no caso específico do megaevento de 1997/1998, a média pluviométrica da região foi influenciada de tal forma que, para o ano de 1998, ela foi de apenas 63,8 mm caracterizando-se, em termos climáticos, em verdadeiro desastre ENOS para a região.

Como reflexo direto na economia, segundo dados da FIBGE (2001) pode-se citar a drástica quebra na produção de milho que, em 1997, foi de 136 t e em 1998 caiu para apenas 3,1 t enquanto na de feijão passou de 540 t em 1997 para apenas $40 \mathrm{t}$ em 1998. Na pecuária bovina o efeito também foi bastante significativo haja vista que o rebanho da região, que em 1996 era de 8.030 cabeças, foi reduzido para apenas

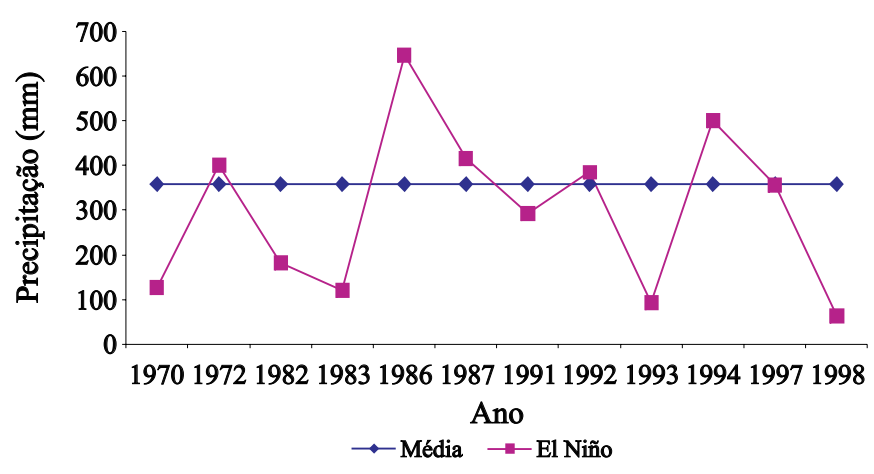

Figura 7. Médias pluviométricas referentes aos anos El Niño - Picuí, PB 
2.185 cabeças em 1998 e para 2.100 cabeças em 1999, ainda como conseqüência do megaevento 1997/98.

Um fato importante de se mencionar é que, como reflexo direto das secas sucessivas acentuadas pelos eventos ENOS e também pela falta das políticas públicas, os municípios, a exemplo de Picuí, que já foi conhecido pela quantidade e qualidade de sua carne de sol, passam de exportadores para importadores de alimentos, causando um empobrecimento ainda maior da região.

Aplicando-se o Assistat 6.2 (teste de Wilcoxom-MonnWhitney) verifica-se, através da comparação das médias que, realmente, existe diferença significativa a nível de $10 \%$ de probabilidade entre os períodos com e sem influência do evento para o município de Picuí.

A Figura 8 mostra a pluviometria de Sumé (Cariri paraibano) referente aos anos El Niño, observando-se que 75\% dos valores ficam abaixo da média histórica do município.

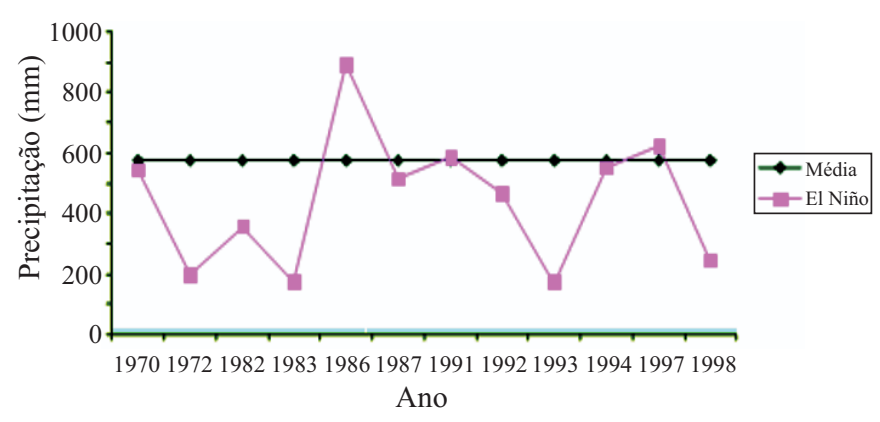

Figura 8. Médias pluviométricas referentes aos anos El Niño - Sumé, PB

Um fato interessante de se observar na Figura 8, é o pico pluviométrico referente ao El Niño 1986/87, fato este semelhante ao que ocorreu nos demais municípios estudados. É preciso levar em consideração que a instalação deste El Niño moderado, como os demais, se deu após o período chuvoso para a região e, em termos de chuvas, o ano de 1986 foi considerado normal. As quedas pluviométricas deste evento só aconteceram em 1987, quando ele atuou efetivamente na estação chuvosa dos municípios, cujas médias pluviométricas ficaram abaixo das médias históricas afetando, assim, a produção agropecuária. Correlacionando-se este evento El Niño com as TSM do Oceano Atlântico para o período de junho de 1986 a julho de 1987 verifica-se, para o ano de 1986, que o Atlântico Norte apresentou anomalias negativas enquanto o Atlântico Tropical e Sul anomalias positivas, caracterizando o dipolo do Atlântico, favorável ao aumento das precipitações no semi-árido. Para o ano de 1987 o Atlântico Norte apresentou anomalias negativas nos meses de janeiro e fevereiro mas positivas de março a junho, e o Atlântico Tropical e Sul apresentaram anomalias positivas, para todo o período, não se caracterizando, de fato, uma situação de dipolo no Atlântico para o ano de 1987, situação que, juntamente com o evento moderado El Niño, acarretou a diminuição das precipitações.
Avaliando-se os índices das precipitações para o município de Sumé, evidencia-se a influência dos megaeventos de 1982/1983 e 1997/1998 e das TSM do Oceano Atlântico, cujo reflexo na queda das precipitações é bastante acentuado; a exemplo dos demais municípios estudados, o evento de 1993 também resultou em precipitações baixíssimas, com reflexos evidentes nas produções agrícola e pecuária. Segundo dados da FIBGE (2001), em 1992 o município de Sumé contava com 15.125 cabeças de gado, em 1993 este número caiu para 8.400 cabeças e em 1994 chegou a apenas 6.720 cabeças. O megaevento 1997/1998 também gerou redução no rebanho bastante significativo, caindo de 10.534 cabeças em 1997 para apenas 6.320 cabeças em 1999; já em relação à produção de feijão, que em 1996 foi de 400 t, caiu para a insignificante quantidade de $6 \mathrm{t}$ em 1999, explicitando o efeito danoso do evento para a região e caracterizando a situação de vulnerabilidade em que se encontra aquela população.

Após o estudo estatístico, se encontrou, através do Assistat versão 6.2 (teste de Wilcoxom-Monn-Whitney), diferença significativa a nível de $5 \%$ de probabilidade entre as médias pluviométricas com e sem influência do El Niño, para o município.

\section{CONCLUSÕES}

1. O fenômeno ENOS e as TSM do Oceano Atlântico influenciam na pluviometria do Estado da Paraíba, levando a crer que essas influências podem ter gerado perdas significativas na produção agropecuária do Estado.

2. Para os municípios de Sousa (Alto Sertão) e Sumé (Cariri), esta diferença significativa também é de $5 \%$, enquanto para Picuí (Curimataú) é de 10\%.

3. De maneira geral, esses estudos apontaram para o fato de ter havido uma queda nas médias pluviométricas anuais do Estado da Paraíba, ao longo das décadas estudadas.

\section{LITERATURA CITADA}

Brasil. Congresso. Senado Federal. Comissão El Niño. Relatório Final. Relator Waldeck Ornelas. Brasília: Senado Federal/ Secretaria Especial de Editoração e Publicações, 1997. 192p.

CLIMERH. Anomalias La Niña 2002. http://www.climerh.rctsc.br/nino. 13 Jan. 2002.

CPTEC. Previsões 1998. http://www.cptec.inpe.br 21 Jan. 2000.

FIBGE. Informações parciais sobre o censo 2000. http:/ www.ibge.gov.br. 10 Out. 2001.

Moura, A. D.; Schukla, J. On the dynamics of droughts in Northeast Brazil: observations, theory and numerical experiments with general circulation model. Journal of Atmospheric Sciences, v.38, p.2663 - 2675. 1981.

Nicholson, S. E. Progress physical geography. In: Sistemas de alerta temprana para casos de sequía y desertificación. OMM-n.906, Genebra, 1999. 12p. 